\title{
Frequency of hyaline membrane disease in preterm infants after prenatal corticosteroid prophylaxis.
}

\author{
Anna Mihaylova', Stanislav Gueorguiev ${ }^{2}$, Nikoleta Parahuleva ${ }^{3}$, Emilia Karaslavova ${ }^{4}$, Milena \\ Sandeva $^{5}$, Elina Petkova-Gueorguieva ${ }^{2}$, Stanislava Ivanova ${ }^{6 *}$, Kalin Ivanov ${ }^{6}$, Ekaterina Uchicova ${ }^{3}$ \\ ${ }^{1}$ Medical College, Medical University Plovdiv, Bulgaria \\ ${ }^{2}$ Faculty of Pharmacy, Department of Pharmaceutical Sciences, Medical University of Plovdiv, Plovdiv, Vasil Aprilov \\ Blvd. 15-A, Bulgaria \\ ${ }^{3}$ Department of Obstetrics and Gynecology, Medical University Plovdiv, Bulgaria \\ ${ }^{4}$ Biomedical Analysis Ltd, Plovdiv, Bulgaria \\ ${ }^{5}$ Department Obstetrics Care, Medical University Plovdiv, Bulgaria \\ ${ }^{6}$ Faculty of Pharmacy, Department of Pharmacognosy and Pharmaceutical Chemistry, Medical University of Plovdiv, \\ Plovdiv, Vasil Aprilov Blvd. 15-A, Bulgaria
}

\begin{abstract}
Premature birth is a serious medical, social and economic problem. Its consequences are multiple health complications leading to high neonatal mortality worldwide. Respiratory insufficiency and surfactant deficiency significantly increase the risk of developing Hyaline Membrane Disease (HMD) and other forms of Respiratory Distress (RDS). These are the most common causes of death in premature babies. In prenatal and neonatal medicine, new and adaptive prophylaxis is being implemented to reduce the risk of death of premature babies and reduce the development of health complications. The goal of effective corticosteroid prophylaxis is to reduce mortality, reduce complications in prenatal new-borns, and shorten their stay in neonatal and intensive units respectively. A retrospective study of 167 preterm infants was conducted, of which $89(53.3 \%)$ had prophylaxis with dexamethasone. In $25(15 \%)$ of preterm infants, there was a Hyaline Membrane Disease (HMD) and $101(60.5 \%)$ developed other forms of Respiratory Distress Syndrome (RDS). The results obtained show that the incidence of HMD in preterm infants is mediated by the early gestational age and advanced age of the mother, and decreased by corticosteroid therapy.
\end{abstract}

Keywords: Premature birth, Hyaline membrane disease, Preterm infants, Corticosteroid prophylaxis.

\section{Introduction}

Premature birth is not only a medical but also a serious socioeconomic problem. It is the most common cause of neonatal mortality in developed countries [1-6]. In Bulgaria, statistics show that $10-12 \%$ of all pregnancies end with premature birth. Despite the number of studies in this direction and the efforts made by obstetricians, the tendency to increase the number of preterm births has continued over the last decade $[7,8]$. Approximately 15 million premature babies are born every year [1]. One of the pathological syndromes of preterm infants is precisely related to lung development and is referred to as a Hyaline Membrane Disease (HMD). It is caused by a deficiency in the synthesis of surfactant combined with structural immaturity of the lungs. HMD affects $1 \%$ of premature infants in the world and is the leading cause of death in this patient group [9-11].

Respiratory distress syndrome is another common cause leading to death among premature infants [9]. In order to reduce the incidence of preterm births, adequate and specialized prenatal care is essential. They should be individually tailored and take into account the complex of risk predispositions for each particular case of pregnancy $[7,10]$.

According to a number of studies on prenatal corticosteroid therapy, it is assumed that pre-birth steroids reduce the rate of death and morbidity in premature infants with very low birth weight $[12,13]$. In meta-analysis of corticosteroid prophylaxis studies, it was concluded that the intrauterine corticosteroid effect resulted in a $50 \%$ reduction in neonatal Respiratory Distress Syndrome (RDS) [3]. 


\section{Purpose}

The purpose of this study is to determine the causes and incidence of HMD and RDS in preterm infants after prenatal corticosteroid prophylaxis of the mother.

\section{Materials and Methods}

A retrospective study is carried out at the clinic of Obstetrics and Gynaecology, University Multiprofile Hospital for Active Treatment St. George-Plovdiv, Bulgaria for the period from April 2015 to March 2016. A documentary method has been used primarily, with primary data on pre-term infants recruited from "Medical case history", "Maternal epicrisis" and "Newborn child's epicrisis". Two groups of new-borns are identified on the basis of available or absent prenatal corticosteroid therapy. Children whose mothers have a prophylactic corticosteroid administration are considered to be "cases" or a workgroup, and those without prenatal prophylaxis are "controls" or a control group. For the purposes of the survey, additional intragroup regrouping is carried out on the basis of some indicators: according to the gestational week in which the birth occurred, the new-borns are divided into: early premature born up to 32 gestational weeks and late prematurely born from 32 to 36 gestational weeks $+6 \mathrm{~d}$; whether or not a prophylactic corticosteroid course has been completed; the weight of newborns; living and died new-borns. For each patient an individual research protocol is completed-a questionnaire specifically designed for the purposes of the study. The data was entered and processed with the IBM SPSS Statistics Ver. 19.0 statistical package. For a significance level where the zero hypothesis is rejected, $\mathrm{p}<0.05$ is taken.

\section{Results and Discussion}

167 preterm infants were examined, with the mean gestational week of birth being $32.42 \pm 3.38$. From the surveyed $89 / 53.3 \%$ are girls and $78 / 46.7 \%$ are boys. In $89 / 53.3 \%$, prophylaxis with dexamethasone was performed. The highest is the percentage of cases with unfinished corticosteroid prophylaxis, i.e. one application was applied-45/51.1\%, and the cases with finished dexamethasone prophylaxis represented the remaining sum of 2 and 3 applications-43/49.4\%. In $25 / 15 \%$ of preterm infants, there was developed hyaline membrane disease, while $101 / 60.5 \%$ developed a different forms of Respiratory Distress Syndrome (RDS) (Tables 1 and 2).

Table 1. Premature infants with HMD.

\begin{tabular}{lll}
\hline & Number & Percent \\
\hline No & 142 & 85.0 \\
\hline Yes & 25 & 15.0 \\
\hline Total & 167 & 100.0 \\
\hline
\end{tabular}

Table 2. Premature infants with other forms of RDS.

\begin{tabular}{lll}
\hline No & 66 & 39.5 \\
\hline Yes & 101 & 60.5 \\
\hline Total & 167 & 100.0 \\
\hline
\end{tabular}

Of the total registered preterm infants with some (other) health complications are nearly $2 / 3$ of the new-borns-107/64.1\% of the cases (Table 3 ). The $3.6 \%$ difference between new-born with RDS and those with all other disabilities shows that in preterm infants the respiratory system is primary damaged. Of the other established health complications in preterm infants, the most common complications are: transient tachypnea +hypoventilation+dyspnoea-13/12.4\%. The following indicators by incidence (here as single complications) are pulmonary edema-10/9.5\% of the cases and pulmonary hypoventilation, also at $10 / 9.5 \%$. Further infection is present in $8 / 7.6 \%$ of new-born infants. In 6 new-born infants, polysystemic combined disorders were observed-apart from respiratory disorders, there was also intraventricular haemorrhage, and in one case RDS was associated with cardiovascular disorder. It should be noted that most of the new-born children have registered polypathology, which includes several damages of the respiratory system. In summary, pathology in $94.3 \%$ in preterm infants includes mainly single or combined respiratory disorders. The registered cases that have only extra-pulmonary pathology are a total of 6 cases: $4 / 3.8 \%$ of cases with acute kidney failure and $2 / 1.9 \%$ with cardiovascular disease. This relative part represents only $5.7 \%$ of all registered complications in preterm infants.

Table 3. Other health complications in preterm infants.

\begin{tabular}{lll}
\hline & Number & Percent \\
\hline No & 60 & 35.9 \\
\hline Yes & 107 & 64.1 \\
\hline Total & 167 & 100.0 \\
\hline
\end{tabular}

It was surveyed what is the incidence of HMD in preterm infants in the cases with prophylaxis or without prophylaxis with dexamethasone. It was found that the incidence of HMD is with $9.2 \%$ higher in preterm infants whose mothers had prenatal corticosteroid prophylaxis (Table 4).

Table 4. Frequency of HMD in dexamethasone prophylactic group and non-prophylactic group.

\begin{tabular}{|c|c|c|c|c|c|}
\hline & & & \multicolumn{2}{|c|}{ Existence of HMD } & \multirow[t]{2}{*}{ Total } \\
\hline & & & No & Yes & \\
\hline \multirow{4}{*}{$\begin{array}{l}\text { Dexamethasone } \\
\text { prophylactic }\end{array}$} & No & Number & 70 & 8 & 78 \\
\hline & & $\%$ & $89.7 \%$ & $10.3 \%$ & $100.0 \%$ \\
\hline & Yes & Number & 72 & 17 & 89 \\
\hline & & $\%$ & $80.9 \%$ & $19.1 \%$ & $100.0 \%$ \\
\hline Total & & Number & 142 & 25 & 167 \\
\hline
\end{tabular}




\begin{tabular}{llll}
\hline$\%$ & $85.0 \%$ & $15.0 \%$ & $100.0 \%$ \\
\hline
\end{tabular}

According to the data obtained, the risk to develop HMD of corticosteroid prophylaxis increases more than twice $(\mathrm{OR}=2.366$ 95\% $\mathrm{CI}=0.937-5.094)$. As this result required additional analysis, we checked the average gestational week and maternal age depending on whether the new-born children have HMD and if there was applied a corticosteroid prophylaxis (Tables 5 and 6). It was found that new-born infants who have registered HMD were born 3.127 gestational weeks earlier than those who did not develop HMD (Table 5). Mothers whose new-born infants have HMD are 2.6 y older than those of whom the new-born children do not have the disease. Both differences were statistically significant $(p<0.05)$, which also showed the significant factorial influence of the gestational week and the maternal age on the occurrence of HMD in preterm infants. Table 3 also shows that prenatal prophylaxis with dexamethasone was performed in those pregnant women who had given birth approximately 2 gestational weeks earlier compared to the gestational week of birth of infants without prophylaxis. The difference found was significant $(\mathrm{p}=0.000)$.

Table 5. Dependence between gestational week, mother's age and HMD.

\begin{tabular}{|c|c|c|c|c|c|c|c|}
\hline & $\begin{array}{l}\text { Existen } \\
\text { ce of } \\
\text { HMD }\end{array}$ & $\begin{array}{l}\text { Numbe } \\
r\end{array}$ & $\begin{array}{l}\text { Averag } \\
\text { e }\end{array}$ & $\begin{array}{l}\text { Standar } \\
\text { d } \\
\text { deviatio } \\
n\end{array}$ & $\mathbf{u}$ & $\mathbf{p}$ & $\begin{array}{l}\text { Average } \\
\text { differenc } \\
\text { e }\end{array}$ \\
\hline \multirow{2}{*}{$\begin{array}{l}\text { Gestational } \\
\text { week of } \\
\text { birth }\end{array}$} & Yes & 25 & 29.76 & 3.677 & \multirow{2}{*}{$\begin{array}{l}-451 \\
5\end{array}$} & \multirow{2}{*}{$\begin{array}{l}0.00 \\
0\end{array}$} & \multirow[t]{2}{*}{-3.127} \\
\hline & No & 142 & 32.89 & 3.104 & & & \\
\hline \multirow{2}{*}{$\begin{array}{l}\text { Mother's } \\
\text { age }\end{array}$} & Yes & 25 & 28.48 & 4.556 & \multirow{2}{*}{$\begin{array}{l}249 \\
9\end{array}$} & \multirow{2}{*}{$\begin{array}{l}0.01 \\
6\end{array}$} & \multirow[t]{2}{*}{2.635} \\
\hline & No & 142 & 25.85 & 6.319 & & & \\
\hline
\end{tabular}

Table 6. Dependence between gestational week, mother's age and dexamethasone prophylactic.

\begin{tabular}{|c|c|c|c|c|c|c|c|}
\hline & Dexamethasone prophylactic & Number & Average & $\begin{array}{l}\text { Standard } \\
\text { deviation }\end{array}$ & $\mathbf{u}$ & $\mathbf{p}$ & Average difference \\
\hline \multirow{2}{*}{$\begin{array}{l}\text { Gestational week of } \\
\text { birth }\end{array}$} & Yes & 89 & 31.51 & 3.458 & -3.893 & 0.000 & -1.956 \\
\hline & No & 78 & 33.46 & 2.970 & & & \\
\hline \multirow[t]{2}{*}{ Mother's age } & Yes & 89 & 26.40 & 6.255 & 0.369 & 0.712 & 0.353 \\
\hline & No & 78 & 26.05 & 6.060 & & & \\
\hline
\end{tabular}

It was surveyed what is the average gestational week of birth and maternal age when combining: prenatal corticosteroid prophylaxis, presence or absence of HMD or RDS (Tables 7 and 8).

It was found that if the new-borns had undergone prophylaxis with dexamethasone and have HMD, they were born in the earliest gestational week-28.82 \pm 3.88 gestational weeks, which occurred more than 3 gestational weeks earlier than infants who have undergone prophylaxis and who have not developed HMD- $32.14 \pm 3.08$ gestational weeks (Table 7). Mothers of new-born children who have been prophylaxis with dexamethasone and their new-born children with HMD have the highest average age of $29.88 \pm 4.15 \mathrm{y}$, which is $1.3 \mathrm{y}$ older than the pregnant women whose new-born children have undergone prophylaxis and do not have an HMD.

Table 7. Dependence between gestational week, prenatal dexamethasone prophylactic and HMD.

\begin{tabular}{|c|c|c|c|c|c|c|c|c|c|}
\hline \multicolumn{2}{|c|}{ Dexamethasone prophylactic } & \multirow{2}{*}{$\begin{array}{l}\text { Existence } \\
\text { HMD } \\
\text { Yes }\end{array}$} & \multirow{2}{*}{ of } & \multirow{2}{*}{$\begin{array}{l}\text { Number } \\
8\end{array}$} & \multirow{2}{*}{$\begin{array}{l}\text { Average } \\
31.75\end{array}$} & \multirow{2}{*}{$\begin{array}{l}\begin{array}{l}\text { Standard } \\
\text { deviation }\end{array} \\
2.659\end{array}$} & \multirow{2}{*}{$\begin{array}{l}\mathbf{u} \\
-1.743\end{array}$} & \multirow{2}{*}{$\begin{array}{l}\mathbf{p} \\
0.085\end{array}$} & \multirow{2}{*}{$\begin{array}{l}\begin{array}{l}\text { Average } \\
\text { difference }\end{array} \\
-1.907\end{array}$} \\
\hline No & Gestational week of birth & & & & & & & & \\
\hline & & No & & 70 & 33.66 & 2.958 & & & \\
\hline & Mother's age & Yes & & 8 & 25.50 & 4.106 & -0.270 & 0.788 & -0.614 \\
\hline & & No & & 70 & 26.11 & 6.264 & & & \\
\hline \multirow[t]{4}{*}{ Yes } & Gestational week of birth & Yes & & 17 & 28.82 & 3.779 & -3.820 & 0.000 & -3.315 \\
\hline & & No & & 72 & 32.14 & 3.078 & & & \\
\hline & Mother's age & Yes & & 17 & 29.88 & 4.152 & 3.416 & 0.002 & 4.299 \\
\hline & & No & & 72 & 25.58 & 6.406 & & & \\
\hline
\end{tabular}


Table 8. Dependence between gestational week, prenatal dexamethasone prophylactic and RDS.

\begin{tabular}{|c|c|c|c|c|c|c|c|c|c|}
\hline \multicolumn{2}{|c|}{ Dexamethasone prophylactic } & \multirow{2}{*}{$\begin{array}{l}\text { Existence } \\
\text { RDS } \\
\text { Yes }\end{array}$} & \multirow{2}{*}{ of } & \multirow{2}{*}{$\begin{array}{l}\text { Number } \\
40\end{array}$} & \multirow{2}{*}{$\begin{array}{l}\text { Average } \\
33.45\end{array}$} & \multirow{2}{*}{$\begin{array}{l}\begin{array}{l}\text { Standard } \\
\text { deviation }\end{array} \\
2.745\end{array}$} & \multirow{2}{*}{$\begin{array}{l}\mathbf{u} \\
-0.035\end{array}$} & \multirow{2}{*}{$\begin{array}{l}\mathbf{P} \\
0.972\end{array}$} & \multirow{2}{*}{$\begin{array}{l}\begin{array}{l}\text { Average } \\
\text { difference }\end{array} \\
-0.024\end{array}$} \\
\hline No & Gestational week of birth & & & & & & & & \\
\hline & & No & & 38 & 33.47 & 3.228 & & & \\
\hline & Mother's age & Yes & & 40 & 25.85 & 6.171 & -0.299 & 0.766 & -0.413 \\
\hline & & No & & 38 & 26.26 & 6.017 & & & \\
\hline \multirow[t]{4}{*}{ Yes } & Gestational week of birth & Yes & & 61 & 31.44 & 3.797 & -0.252 & 0.801 & -0.200 \\
\hline & & No & & 28 & 31.64 & 2.628 & & & \\
\hline & Mother's age & Yes & & 61 & 27.80 & 6.226 & 3.282 & 0.001 & 4.446 \\
\hline & & No & & 28 & 23.36 & 5.230 & & & \\
\hline
\end{tabular}

New-born children who have not undergone prophylaxis with dexamethasone and who have developed HMD were born in $31.75 \pm 2.66$ gestational week, which makes a difference of 2.93 gestational weeks of birth between new-born children who have undergone prophylaxis and have developed HMD-28.82 \pm 3.78 . When compared to the average gestational week of birth and maternal age of new-born children who have undergone prophylaxis with dexamethasone and having RDS (Table 5), there were no significant differences observed in new-born children, as was the case with HMD (Table 7). The only statistically significant difference was recorded in the average age of the mother, and the pregnant women with dexamethasone prophylaxis and with presence of RDS are 4.5 y older than pregnant women whose new-born children have undergone prophylaxis and did not develop RDS. From the results so obtained, it can be concluded that the gestational week of birth does not affect the RDS only the advanced maternal age is associated with the higher incidence of RDS.

Based on the results obtained above (Table 7), a multifactorial logistic-regression analysis was performed to study the combined effect of gestational week of birth, maternal age, and dexamethasone prophylaxis on HMD. In this model it was found that in the combined effect of the three tested factors as independent remain the gestational week of birth and the mother's age with the following calculated risks for the occurrence of HMD (OR for gestational weeks of birth $=2.686$ 95\% $\mathrm{CI}=1.048-6,882 ; \quad$ OR maternal age $=4.130 \quad 95 \%$ $\mathrm{CI}=1.530-11.148$ ). Dexamethasone prophylaxis loses its significant impact on HMD in this combined regression model, also taking into account a reduction in disease risk compared to the registered risk in the single factor regression analysis $(\mathrm{OR}=1.66395 \% \mathrm{CI}=0.642-4.306)$.

As a conclusion, it can be summarized that dexamethasone, despite the result obtained, is not really associated with HMD, and the actual causes of the result obtained in Table 1 are the earlier gestational week of birth and the advanced maternal age.

The new-born children in the study were divided in groups, depending on whether they were born before or after 29 gestational weeks, whether they have or have not undergone prophylaxis with dexamethasone and whether or not they have HMD. It was found that out of all 27 new-born children with dexamethasone prophylaxis and born before 29 gestational weeks the majority of them did not develop HMD-16 (59.3\%). In those born after 29 gestational week, from 62 new-born infants with dexamethasone prophylaxis, 56 (90.3\%) did not develop the disease, indicating an even better protective effect of corticosteroids against the disease, but it should be noted that, 6 of the new-born children born before 29 gestational week did not develop HMD and have not undergone prophylaxis with dexamethasone. New-born children with RDS whose mothers have prenatally undergone prophylaxis with dexamethasone were $17.2 \%$ more than those who had RDS and had no corticosteroid prophylaxis. According to these data, the difference between the compared relative shares found was statistically significant $\left(x^{2}=5.179, p=0.023\right)$. The risk of developing some form of RDS when applying corticosteroid prophylaxis according the obtained results is increased nearly two and a half times compared to nonapplying this preventative measure $(\mathrm{OR}=2.070 \quad 95 \%$ $\mathrm{CI}=1.102-3.887)$.

Taking into account the result about the incidence of RDS in prenatal corticosteroid prophylaxis and non-prophylaxis, the studied patients were divided into those born before 29 gestational weeks, and afterwards. It was found that new-born babies born before 29 gestational week, had corticosteroid prophylaxis and have a RDS are $21 / 77.8 \%$, and those who were born before 29 gestational week have a RDS and without corticosteroid prophylaxis are $2 / 33.3 \%$. The $44.5 \%$ difference between the compared relative shares is statistically significant (Fishers' Exact Test $=0.049$ ). It is difficult to explain the result obtained, which is similar, but it is not with so clearly expressed difference between the compared percentages and in those born after 29 gestational weeks. It should be noted here that the share of new-born children before 29 gestational week, who have RDS and are without corticosteroid prophylaxis, is composed of only 2 cases, and this does not allow us to confidently make conclusions in this case from such small statistical methods.

As a summary of the dependencies between dexamethasone prophylaxis, gestational week of birth and maternal age, the 
presence of HMD and RDS, it can be concluded that the presence of HMD is mediated by the early gestational week, advanced maternal age and is limited by corticosteroid prophylaxis, but this cannot be said for RDS. And in the case of dividing the patients depending on whether or not they have a HMD, the completed or uncompleted corticosteroid course of prophylaxis has proven to be the same as in the case of newborn children with or without dexamethasone prophylaxis. It was again found that new-born children with HMD had a higher incidence in the case of a completed dexamethasone prophylaxis course, with a statistically significant difference in the compared shared shares (Fisher's Exact Test=0.016). Taking into account the result obtained in Table 1, preterm infants were divided into groups according to the following indicators: completed or uncompleted prophylactic course with dexamethasone, presence or absence of HMD and those born before and after 30 gestational week. In those born before 30 gestational week if they have an uncompleted course of prophylaxis with dexamethasone, i.e. 1 application is applied, $8 / 80 \%$ does not develop HMD, and if the course is completed this percentage is $14 / 60.9 \%$. Those born after 30 gestational weeks having an uncompleted corticosteroid course and are without HMD are 32/94.1\% and those with completed corticosteroid course and without the disease are $16 / 80 \%$.

From the results so obtained, one-time application of dexamethasone (defined as a short-term course of prophylaxis) is likely to have a better prophylactic effect on HMD than two or three long-term prophylactic treatments. The combined influence of the indicators is analysed: completed or uncompleted course with dexamethasone and gestational week of birth on the HMD occurrence. Again as an independent factor remained the influence of the gestational week of birth and the completed course with dexamethasone lost its significant influence on HMD.

\section{Conclusion}

The preterm infants with hyaline membrane disease with dexamethasone prophylaxis were born averagely over than 3 gestational weeks earlier and their mothers being $4 \mathrm{y}$ older than those whose new-born children do not have the disease. In preterm infants, the relationship between maternal age and dexamethasone prophylaxis and the presence of respiratory distress syndrome is maintained.

The one-time prenatal application of dexamethasone (defined as a short-term prophylactic course) has a better prophylactic effect on HMD than 2 or 3 corticosteroid applications (longterm prophylactic course).

In the analysis of the combined effect of dexamethasone prophylaxis, the gestational week of birth and the maternal age in preterm infants with HMD, the presence of HMD is mediated by the earlier gestational week of birth, the advanced maternal age, and on this background it is somewhat limited by the prenatal application of corticosteroids.

\section{References}

1. Eunice Kennedy Shriver National Institute of Child Health and Human Development. Preterm labor and birth: Condition information. NIH 2015.

2. Blencowe H, Cousens S, Oestergaard M, Chou D, Moller AB. National, regional and worldwide estimates of preterm birth rates in the year 2010 with time trends since 1990 for selected countries: a systematic analyses and implications. Lancet 2012; 379: 2162-2172.

3. Crowley P. Antenatal corticosteroid therapy: A metaanalysis of the randomized trials 1972-1984. Am J Obstet Gynecol 1995; 173: 322-335.

4. Goldenberg RL, Culhane JF, Iams JD, Romero R. Epidemiology and causes of preterm birth. The Lancet 2008; 371: 75-84.

5. Heaman M, Blanchard J, Gupton A, Moffatt M, Currie R. Risk factors for spontaneous preterm birth among Aboriginal and non-Aboriginal women in Manitoba. Paediatr Perinat Epidemiol 2005; 181-193.

6. Heron M. Deaths: leading causes for 2008. Natl Vital Stat Rep 2012; 60: 1-94.

7. Astolfi P, Zonta LA. Risks of preterm delivery and association with maternal age, birth order, and fetal gender. Hum Reprod 1999; 14: 2891-2894.

8. Iams JD, Romero R, Culhane JF. Primary, secondary, and tertiary interventions to reduce the morbidity and mortality of preterm birth. Lancet 2008; 371: 164-175.

9. Ivanov St. Pregnancy patology, preterm birth. Obstetrics 2014; 195-198.

10. Kamath BD, Macguire ER, McClure EM, Goldenberg RL, Jobe AH. Neonatal mortality from respiratory distress syndrome: lessons for low-resource countries. Pediatrics 2011; 127: 1139-1146.

11. Krueger PM, Scholl TO. Adequacy of prenatal care and pregnancy outcome. J Am Osteopathic Assoc 2000; 100: 485-492.

12. Rodriguez RJ, Martin RJ, Fanaroff AA. Respiratory distress syndrome and its management. Neonatal-perinatal medicine: diseases of the fetus and infant. Mosby, St. Louis, USA 2002; 1001-1011.

13. Rushing S, Ment LR. Preterm birth: A Cost benefit analysis semin perinatal. 2004; 28: 444-450.

\section{*Correspondence to}

Stanislava Ivanova

Faculty of Pharmacy

Department of Pharmacognosy and Pharmaceutical Chemistry

Medical University of Plovdiv

Plovdiv

Vasil Aprilov Blvd. 15-A

Bulgaria 